\title{
Storage stability of whole milk powder produced from raw milk reverse osmosis retentate
}

\author{
Ida Sørensen $^{1}$ - Tommas Neve ${ }^{2} \cdot$ Niels Ottosen $^{3}$. \\ Lotte Bach Larsen $^{1}$ • Trine Kastrup Dalsgaard ${ }^{1}$. \\ Lars Wiking ${ }^{1}$
}

Received: 13 June 2016 / Revised: 30 November 2016 / Accepted: 2 December 2016 /

Published online: 19 December 2016

(C) INRA and Springer-Verlag France 2016

\begin{abstract}
Implementation of reverse osmosis filtration at the dairy farm will reduce the volume of milk, which has to be transported, and thereby potentially reduce energy consumption and $\mathrm{CO}_{2}$ emission. The aim of this study was to examine the quality of whole milk powder produced from reverse osmosis retentate concentrated at the farm. Whole milk powder prepared from reverse osmosis retentate, with a volume concentration factor of 2, was compared to powder from non-concentrated milk, as well as to a range of commercial whole milk powders. A storage experiment of the stability of retentate powder for up to 12 months at room temperature was conducted and evaluated for quality parameters, including proteolysis, oxidation, furosine and colour. The results showed that concentration of the oxidation products hexanal, heptanal and nonanal increased during storage of both retentate powder and powder from non-concentrated milk, but not to a higher extent than found in commercial powder of similar storage conditions. Detectable furosine was higher in powder prepared from non-concentrated milk than that in powder from pre-concentrated milk, and further no changes in colour was found during storage. However, high variation in powder composition between produced powders, especially with regard to moisture content, could have affected some quality parameters. In conclusion, pre-concentrating milk by reverse osmosis at the farm did not have significant effects on the overall quality of the produced milk powders in this study.
\end{abstract}

Keywords Membrane filtration · Oxidation · Proteolysis · Maillard reaction · Furosine

Lars Wiking

lars.wiking@food.au.dk

1 Department of Food Science, Aarhus University, Blichers Allé 20, 8830 Tjele, DK, Denmark

2 Arla Strategic Innovation Centre, Arla Foods, Roerdrumvej 10, 8820 Brabrand, DK, Denmark

3 Arla Foods Ingredients Group P/S, Sønderupvej 26, 6920 Videbæk, DK, Denmark 


\section{Introduction}

Milk powder quality is commonly evaluated in two categories: physical and chemical. The physical quality is related to handling the powder during production (flowability) during shipment (bulk density) and by the consumer (wettability). These attributes are often associated with production-related factors such as atomization and dry matter of the evaporated milk and thereby size distribution and surface composition of the powder particles (Kim et al. 2009; Murrieta-Pazos et al. 2012). However, much of the powder quality depends on the raw material. A high level of proteolytic and lipolytic activities in the milk, due to either bacterial growth or somatic cells, will transfer these qualities to the milk powder and perhaps advance the reactions found in the powder during storage (Celestino et al. 1997). Sert et al. (2016) has in a recent study found a correlation between elevated somatic cell count and loss of functional properties such as solubility, wettability and dispersability of whole milk powder. This resulted in poor texture when the powder was reconstituted into yoghurt.

In relation to chemical quality, nutritional value and flavour may be compromised through alteration of fat and proteins and by oxidation. Therefore, it is of absolute importance to ensure the product quality when implementing new technologies. Heat treatments of the milk prior to drying might denature whey proteins which can then interact with the casein micelles, and thereby alter the functionality (Singh 2007). The Maillard reaction is also catalysed by high temperature, moisture content and $\mathrm{pH}$ and will influence the appearance, colour, flavour, odour and digestibility due to essential amino acids being less accessible after lactosylation (Thomas et al. 2004; Dalsgaard et al. 2007). Furosine is formed as a further stage of lactosylation, when fructoselysine, generated from lactulosyl-lysine, is hydrolysed in acidic conditions during analysis. This rather early stage of Maillard reaction is a good indicator of heat damage, since these products are often found in freshly produced milk powder and UHT milk, and studies have correlated the formation of furosine with especially heat modifications of $\beta$-lactoglobulin (Van Renterghem and De Block 1996). Humidity plays a significant role in Maillard reaction during storage of the powder. Even at low storage temperature, where furosine is not normally formed, humid conditions can accelerate the process (Van Renterghem and De Block 1996). Maillard reaction that reaches some of the end products will often go by the nomination of non-enzymatic browning and will yield a powder with a lower lightness value $\left(\mathrm{L}^{*}\right)$ and more yellowness $\left(\mathrm{b}^{*}\right)$ and redness $\left(\mathrm{a}^{*}\right)$ (Thomas et al. 2004). Oxidation is another aspect that will give unpleasant flavour to the powder and is often associated with surface composition of the particles and storage conditions (Pisecky 1997; Romeu-Nadal et al. 2007). Secondary lipid oxidation products, such as hexanal, heptanal and nonanal, have aromatic properties linked to grassy and floral/citrus notes (Mahajan et al. 2004). Lipid oxidation in milk powder is assumed to be mainly from autoxidation, since enzymatic oxidation in powder is insignificant due to the low water activity (Parkin 2008).

We previously showed that concentrating milk at the farm using reverse osmosis (RO) did not induce any change of free fatty acid concentration and proteolytic activity, provided that raw milk of good quality was used (Sørensen et al. 2016). It was therefore assumed that the products made from the RO retentate, such as powder, would be of similar quality compared to the products made from raw milk. The aim of this study was thus to compare the quality of whole milk powders obtained either from RO 
retentate or from raw milk. In this aim, we produced milk powders from the same raw milk, either pre-concentrated or not on the same spray drying pilot plant, and we characterized the properties of these powers and their storage stability, in comparison to real-scale commercial whole milk powders.

\section{Materials and methods}

\subsection{Production of retentate}

Danish Cattle Research Centre (Aarhus University_Foulum, Tjele, Denmark) provided raw milk for the RO filtration studies. From the bulk tank, $800 \mathrm{~L}$ of milk was transferred to a smaller bulk tank with cooling and stirring system. The milk was a mixture from Danish Holstein and Jersey cows (2:1 ratio). Membrane filtration was conducted at the Danish Cattle Research Centre as a batch process, where the milk circulated between the small bulk tank and the filtration plant (pilot filtration plant produced by GEA, Skanderborg, Denmark), until the desired concentration factor was reached. The filtration was carried out by RO with two $3.8^{\prime \prime} \mathrm{pHt}$ spiral wound membranes produced by Alfa Laval (Lund, Sweden), with a total surface area of $2 \times 4.7 \mathrm{~m}^{2}$. Pressure across the membranes was $30 \mathrm{bar}$, and the process temperature was kept a $4{ }^{\circ} \mathrm{C}$. To produce $400 \mathrm{~L}$ of permeate (with a volume concentration factor of 2 ), a process time of $9 \mathrm{~h}$ was required. All the batches of raw milk had a dry matter of $13.7 \%$, and the RO filtration resulted in retentate with a dry matter of 25.0 and $24.7 \%$. The morning after concentrating the milk, the retentate and $400 \mathrm{~L}$ of fresh raw milk from the same heard was transported to GEA Niro (GEA Process Engineering, Søborg, Demnark) and stored for 1 day at $4{ }^{\circ} \mathrm{C}$, before further processing. This experimental production was conducted as duplicates of both $\mathrm{RO}$ retentate and fresh raw milk on two subsequent days. The samples, 'Non-conc 1' and 'Conc 1' referring to nonconcentrated raw milk and pre-concentrated raw milk, were dried on the same dayon the second day after the production of 'Conc 1' retentate. The procedure was then repeated for 'Non-conc 2' and 'Conc 2'.

\subsection{Powder manufacture and storage}

Before powder production, both the retentate and raw milk batches were thermised at $67{ }^{\circ} \mathrm{C}$ for $90 \mathrm{~s}$ and afterwards evaporated to approximately the same level of dry matter content (41.5-46.8\%), followed by homogenization. The powder was produced as a multistage drying process, with an inlet temperature of $180^{\circ} \mathrm{C}$ and outlet of $75^{\circ} \mathrm{C}$. A system of three-stage fluidized beds was used, and powder fines retrieved from the outlet air were recycled into the drying chamber close to the atomizer nozzle. A schematic overview of the milk treatment and powder production is shown in Fig. 1.

The powders were stored in air and light sealed bags at room temperature of approximately $20^{\circ} \mathrm{C}$ for 3, 6 and 12 months. The atmosphere was not modified, and no vacuum applied to the bags. Aliquots for furosine and oxidation measurements were taken at the indicated time points and stored at $-80{ }^{\circ} \mathrm{C}$ until analysed. The reference powders were acquired from Arla Arinco (Arla Foods, Videbæk, Denmark) and Arla Akafa (Arla Foods, Svenstrup, Denmark) and had been stored at the dairies in bulk 


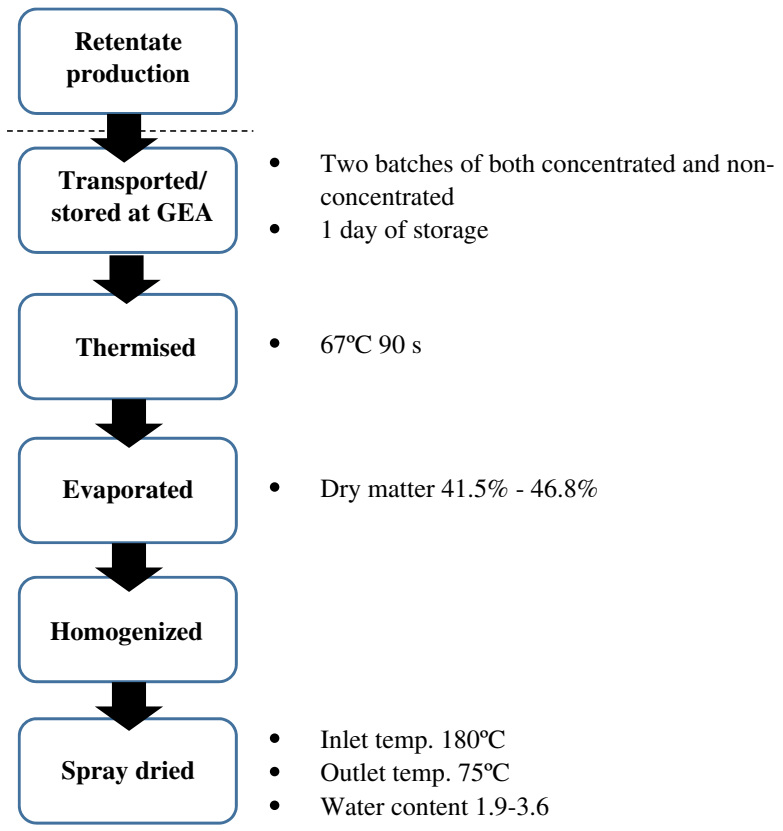

Fig. 1 Process diagram of powder production on pilot spray drier. Included is the pre-concentration step

bags at room temperature. Two reference samples had been stored in sealed package with alternated atmosphere. All the reference samples were acquired and analysed at the same time at the end of the storage experiment. Thus, all the reference samples were produced at different times and as different batches.

\subsection{Powder composition}

\subsubsection{Protein content}

Protein content was estimated by the Kjeldahl method (AOAC 2005), using Kjeltec Instruments (Kjeltec System Autosampler 8460 and Kjeltec System Autoburette 8400 Analyser Unit, Foss, Hillerød, Denmark). The protein content was determined by dissolving a 0.2 g powder sample in $12 \mathrm{~mL} 98 \%$ sulfuric acid and $5 \mathrm{~mL}$ pure hydrogen peroxide. Two Kjeldahl taps (copper sulphate and potassium sulphate, Foss, Hillerød, Denmark) were added to the solution. The samples were then set to react at $420{ }^{\circ} \mathrm{C}$ for $1 \mathrm{~h}$ and $20 \mathrm{~min}$ and added sodium hydroxide $27.5 \%$ to convert the ammonium sulphate into ammonia gas, before being titrated with hydrochloric acid $0.1 \mathrm{M}$. The nitrogen content was multiplied by a factor of 6.38 , to calculate the estimated protein content of the sample.

\subsubsection{Fat content}

Total fat content was measured by the Rose-Gottlieb method (AOAC 2000). A $0.3 \mathrm{~g}$ powder sample was dissolved in $10 \mathrm{~mL}$ demineralized water overnight. Afterwards, $1 \mathrm{~mL}$ ammonia was added to the tubes together with $10 \mathrm{~mL}$ ethanol $96 \%$ and congo red 
indicator solution. The fat phase was then dissolved in $25 \mathrm{~mL}$ diethyl ether and $25 \mathrm{~mL}$ petroleum ether. After $30 \mathrm{~min}$, the fat phase was withdrawn and the solvents evaporate so the fat was left at the bottom of the tube.

\subsubsection{Insoluble particles}

Insoluble particles were measured by dissolving $10 \mathrm{~g}$ of sample in $100 \mathrm{~mL}$ of water using a Solubility Index Mixer (type AC, Labinco BV, Breda, Nederland) for $1.5 \mathrm{~min}$. The samples then rested for $15 \mathrm{~min}$ before being stirred and poured into $50-\mathrm{mL}$ centrifuge tubes and centrifuged for $5 \mathrm{~min}$ at $800 \mathrm{rpm}$ at room temperature. The top $45 \mathrm{~mL}$ was poured off and replaced by water. The samples were stirred before centrifugation was repeated. The amount of sediment was then regarded the insolubility index.

\subsubsection{Surface free fat}

Surface free fat analysis was conducted by Arla Arinco (Videbæk, Denmark). The samples were washed with petroleum ether, filtrated, and the solvent evaporated, so only the surface fat of the particles would be left in the beaker.

\subsubsection{Particle size distribution}

Particle size distribution was determined by sieving $50 \mathrm{~g}$ of sample through a sieve tower with a $630 \mu \mathrm{m}$ and a $400 \mu \mathrm{m}$ metal sieve with an amplitude of 60 for $3 \mathrm{~min}$. The distribution of powder between the sieves was then measured.

\subsection{Proteolysis}

The powder was reconstituted in demineralized water to approximately the same concentration as raw milk and kept for 3 days at $4{ }^{\circ} \mathrm{C}$. The composition of the reconstituted milk was measured by FT-IR (MilkoScan FT2, Foss, Hillerød, Denmark). The level of proteolysis was measured by the reaction between N-terminals of amino groups and fluorescamine and quantified by a standard row of leucine. Thus, the results were measured as Leucine equivalents $\left(\mathrm{mmol} \cdot \mathrm{L}^{-1}\right)$ divided by the total protein content. A description of the fluorescamine assay can be found in the study by Wiking et al. (2002). Results were obtained by analysis on a multi plate reader (BioTek Synergy 2, Holm \& Halby, Brøndby, Denmark) with the Gen5 1.07.5 software (BioTek Instruments, Winooski, VT, United States). The concentration of free N-terminals was then divided by the protein content in the reconstituted milk, to find the relative proteolysis in the sample. The measurements were conducted in triplicates.

\subsection{Oxidation}

The method for measuring oxidation products was adapted from Jensen et al. (2011), on the same equipment, with a few modifications to the procedure. A sample size of $200 \mathrm{mg}$ powder was put into a HPLC tube with $1 \mathrm{~mL}$ water and $5 \mu \mathrm{L} 0.01 \mathrm{mg} \cdot \mathrm{mL}^{-1}$ internal standard (hexanal D12). For subtraction of the volatile compounds into the GC- 
MS, a grey SPME fibre (50/30 um DVB/CAR/PDMS, stableflex $2 \mathrm{~cm}$, Grey-notched) from Supleco (Bellefonte PA, USA) was incubated at $50{ }^{\circ} \mathrm{C}$ for $30 \mathrm{~min}$ and injected into a GC-MS MSD 5975 from Agilent Technologies (Waldbronn, Germany) with an inlet temperature of $275^{\circ} \mathrm{C}$. A mixed external standard was used for quantification of the oxidation products found: hexanal (targeted ion $56 \mathrm{~m} / \mathrm{z}$ and qualifier ions 82 and $72 \mathrm{~m} / \mathrm{z}$ ), heptanal (targeted ion $70 \mathrm{~m} / \mathrm{z}$ and qualifier ions 55,81 and $86 \mathrm{~m} / \mathrm{z}$ ) and nonanal (targeted ion $57 \mathrm{~m} / \mathrm{z}$ and qualifier ions 98,82 and $70 \mathrm{~m} / \mathrm{z}$ ) using hexanal D12 as an internal standard according to Wold et al. (2015) using a target ion of $64 \mathrm{~m} / \mathrm{z}$ and qualifier ions 80 and $92 \mathrm{~m} / \mathrm{z}$.

\subsection{Colour}

Colour was measured by colorimeter (Konica Minolta portable spectrophotometer, Tokyo, Japan), using the parameters L* (lightness), a* (red/green) and b* (yellow/blue). The measurements were conducted as triplicates through a thin transparent plastic bag.

\subsection{Furosine}

The method for furosine measurement was adapted from Jansson et al. (2014). Samples of whole milk powder $(0.15 \mathrm{~g})$ were hydrolysed in $10 \mathrm{~mL} 8 \mathrm{~mol} \cdot \mathrm{L}^{-1}$ hydrochloric acid for $20 \mathrm{~h}$ at $110^{\circ} \mathrm{C}$ and filtered after cooling. The filtrated hydrolysate was diluted 1:4 in $3 \mathrm{~mol} \cdot \mathrm{L}^{-1}$ hydrochloric acid, and $500 \mu \mathrm{L}$ was transferred to HPLC filter vails. Furosine concentration was determined through ion-pair RP-HPLC using a Spherisorb ODS2 $5 \mu \mathrm{m}$ column $\left(250 \times 4.6 \mathrm{~mm}\right.$ i.d.) (Grace Davison, Australia), with $0.06 \mathrm{~mol} \cdot \mathrm{L}^{-1}$ acetate buffer and a flow rate of $0.5 \mathrm{~mL} \cdot \mathrm{min}^{-1}$. The amount of furosine was calculated based on a standard curve with a concentration of $0.3-10 \mu \mathrm{g} \cdot \mathrm{mL}^{-1}$, made from a stock solution of $0.604 \mathrm{mg} \cdot \mathrm{mL}^{-1}$ furosine dihydrochloride $(99.4 \%$ purity) from the PolyPeptide Group (Strasbourg, France).

\subsection{Statistics}

The statistical analysis of variance was processed through the statistical freeware program R 3.0.1 (R Foundation for Statistical Computing, Vienna, Austria). The effects of powder fat content, storage time and protein content, respectively, on surface free fat, oxidation and furosine were analysed by the following model: $\gamma_{i}=\alpha+\beta \chi_{(i)}+\mathrm{e}_{i}$, $i=1, \ldots, 11$; where $\gamma$ was the value of the dependant variable and $\chi$ was the value of the independent variable in samples 1 to 11 and $e_{i}$ as the residual error. $\alpha$ and $\beta$ were the intercept and slope estimated for the linear model. The effects of powder type on proteolysis and colour were tested by the model: $\gamma_{i}=\mathrm{T}_{(\mathrm{i})}+\mathrm{e}_{i} ; i=$ sample $1, \ldots, 11$, where $\gamma$ was the value of the dependant variable and T was the effect of type in samples 1 to 11 and $e_{i}$ as the residual error. Tukey's HSD test (R package agricolae, version 1.24) was applied for evaluation of treatment differences among powder types. Oxidation products as dependant on interaction between storage time and powder type were of the model: $\gamma_{i j}=\mathrm{SP}_{(\mathrm{i} j)}+\mathrm{S}_{(\mathrm{i})}+\mathrm{P}_{(j)}+\mathrm{e}_{i j}$; where $\gamma$ refers to the value of the specific oxidation product as the dependant variable, $S_{i}=$ effect of storage time ( $i=0,3,6,12$ months) and $P=$ effect of powder type ( $j=$ conc, non-conc and reference). $P<0.05$ was used as the significant threshold in all the models. 


\section{Results}

\subsection{Powder composition and characteristics}

Prior to powder production, the raw milk had a fat content of $4.5-4.9 \%$ and a protein content of $3.6 \%$; while the pre-concentrated milk had a fat content of $8.3-8.6 \%$ and a protein content of $6.8-6.9 \%$. After powder production, both batches of powder made from non-concentrated milk had a fat content of 17.8$21.9 \%$ and a protein content of $29.3-30.8 \%$ (Table 1 ). The powders from preconcentrated milk had a fat content of $29.9-31.0 \%$ and a protein content of 26.3-26.5\%. Variation in the powder composition between pre-concentrated and non-concentrated was presumably a result of handling at the spray drying facility. The water content of all the samples was between $1.8-3.5 \%$. The surface free fat varies between $0.17 \mathrm{~g} / 100 \mathrm{~g}$ fat to $2.59 \mathrm{~g} / 100 \mathrm{~g}$ fat, and the highest amounts were found in the powder from pre-concentrated milk. There was a significant $\left(P<0.05 ; R^{2}=0.89\right)$ correlation between the total fat content in the powder and the level of surface free fat. All of the powders made from raw milk and pre-concentrated milk had similar particle size distribution, with about $98 \%$ of the particle mass having a diameter of $400 \mu \mathrm{m}$ or smaller. The instant reference powders had a larger portion of particles in the 630 to $400 \mu \mathrm{m}$ range, and the regular reference powders were more or less equally distributed between the fraction of 630 to $400 \mu \mathrm{m}$ and $400 \mu \mathrm{m}$ to smaller.

\subsection{Proteolysis and oxidation during storage}

Proteolysis was measured as level of free N-terminals in the newly produced powders and subsequently again after 3, 6 and 12 months of storage and compared to commercial powders of different ages as references relative to protein content (Fig. 2). No trend towards increased proteolysis during storage was observed, and only the powder origin had a significant influence on the level of free N-terminals. Overall, the commercial reference powders had a higher level of proteolysis relative to protein content compared to the small-scale produced powder form raw and pre-concentrated milk. The powder from raw milk had the lowest level of proteolysis in spite of being the powder with the highest protein content.

During storage, an increase of the secondary lipid oxidation products hexanal, heptantal and nonanal was found. Interaction between storage time and powder type (powder from RO retentate and non-concentrated milk) was significant (Fig. 3). The hexanal content increased from below quantification limit of $10 \mathrm{ng} / 100 \mathrm{mg}$ sample in freshly produced powder to about $98 \mathrm{ng} / 100 \mathrm{mg}$ sample in 12-month-old powder from raw milk and $66 \mathrm{ng} / 100 \mathrm{mg}$ sample in powder from pre-concentrated milk. Only the reference powder stored in a bulk bag for 12 months showed detectable concentrations of oxidation products (Ref. regular 12 month in Table 1), with a hexanal concentration of $144 \mathrm{ng} / 100 \mathrm{mg}$ sample (Fig. 3a). Even with a significant influence of powder origin on hexanal development during storage, the specific powder composition did not have any impact on the result. There is a significant effect $(P=0.0015)$ of interaction between storage time and moisture content on the hexanal concentration. Heptanal increased from below quantification limit of $5 \mathrm{ng} / 100 \mathrm{mg}$ sample for both raw and pre- 
Table 1 Composition and physical characterization of small-scale powders produced from non-concentrated (non-conc) raw milk and raw milk pre-concentrated (conc) at the farm from reverse osmosis, on two subsequent days (1 and 2) of production, and several commercial reference samples (Ref.) - both instant and regular stored in bulk bags for up to 12 months and two reference powders stored in sealed bags with altered air composition

\begin{tabular}{|c|c|c|c|c|c|c|c|c|}
\hline & \multicolumn{4}{|c|}{ Composition } & \multicolumn{4}{|c|}{ Particle size distribution } \\
\hline & $\begin{array}{r}\text { Fat } \\
\%\end{array}$ & $\begin{array}{r}\text { Protein } \\
\%\end{array}$ & $\begin{array}{r}\text { Water } \\
\%\end{array}$ & $\begin{array}{r}\text { Surface fat } \\
\mathrm{g} / 100 \mathrm{~g} \\
\text { fat }\end{array}$ & $\begin{array}{r}\text { Insoluble } \\
\text { particles }\end{array}$ & $\geq 630 \mu \mathrm{m}$ & $630-400 \mu \mathrm{m}$ & $\leq 400 \mu \mathrm{m}$ \\
\hline Non-conc 1 & 17.81 & 30.78 & 3.55 & 0.17 & 0.2 & 0.20 & 1.20 & 98.60 \\
\hline Conc 1 & 29.89 & 26.47 & 2.17 & 1.57 & 0.2 & 0.90 & 2.20 & 96.90 \\
\hline Non-conc 2 & 21.89 & 29.29 & 2.81 & 0.85 & 0.1 & 0.58 & 1.00 & 98.42 \\
\hline Conc 2 & 31.00 & 26.26 & 1.87 & 2.59 & 0.2 & 0.26 & 1.82 & 97.92 \\
\hline Ref. regular fresh & 28.24 & 23.63 & 3.17 & 0.99 & 0.1 & 0.30 & 53.19 & 46.52 \\
\hline $\begin{array}{l}\text { Ref. regular } \\
12 \text { month }\end{array}$ & 27.97 & 23.45 & 3.38 & 0.83 & 0.1 & 0.16 & 37.36 & 62.48 \\
\hline $\begin{array}{l}\text { Ref. instant } \\
6 \text { month }\end{array}$ & 26.47 & 26.89 & 3.31 & 1.14 & 0.1 & 4.49 & 64.22 & 31.29 \\
\hline Ref. instant fresh & 27.91 & 23.97 & 2.71 & 1.49 & 0.1 & 2.30 & 83.21 & 14.49 \\
\hline $\begin{array}{l}\text { Ref. regular } \\
3 \text { month }\end{array}$ & 25.76 & 24.17 & 3.04 & 0.88 & 0.1 & 0.20 & 44.10 & 55.70 \\
\hline $\begin{array}{l}\text { Ref instant sealed } \\
12 \text { month }\end{array}$ & 28.36 & 23.54 & 2.85 & 1.70 & 0.1 & 0.98 & 68.98 & 30.04 \\
\hline $\begin{array}{l}\text { Ref regular } \\
\text { sealed } \\
12 \text { month }\end{array}$ & 26.34 & 23.99 & 3.22 & 1.64 & 0.1 & 0.52 & 6.13 & 93.35 \\
\hline
\end{tabular}

concentrated milk powder to about $21 \mathrm{ng} / 100 \mathrm{mg}$ sample in the raw sample and $15 \mathrm{ng} /$ $100 \mathrm{mg}$ sample in the pre-conc. sample (Fig. 3b). The 12-month-old reference sample (Ref. regular 12 month in Table 1) was comparable to the raw sample on heptanal content with $24 \mathrm{ng} / 100 \mathrm{mg}$ sample. Like hexanal, there is a significant $(P=0.002)$ interaction between storage time and moisture content. Nonanal was below the detection limit of $5 \mathrm{ng} / 100 \mathrm{mg}$ sample in all the freshly produced samples and increased to $9 \mathrm{ng} / 100 \mathrm{mg}$ in the raw milk powders and $10 \mathrm{ng} / 100 \mathrm{mg}$ in the pre-conc. powders after 12 months of storage (Fig. 3c). The increase of nonanal during storage was significant for all of them. After 6 months of storage, the raw milk powder had reached an average level of nonanal comparable to what was also found after 12 months of storage. The concentration of nonanal powder from pre-concentrated milk increased significantly from 6 to 12 months of storage and in the end exceeded the level found in the raw milk powder samples, and a significant interaction between powder type and storage time was found. However, the fat and protein composition of the powders did not have a direct impact on the nonanal development. The 12-month-old reference sample (Ref. regular 12 month in table 1) had a nonanal content of $6 \mathrm{ng} / 100 \mathrm{mg}$ sample and is there for lower than both powder from raw milk and preconcentrated milk. 


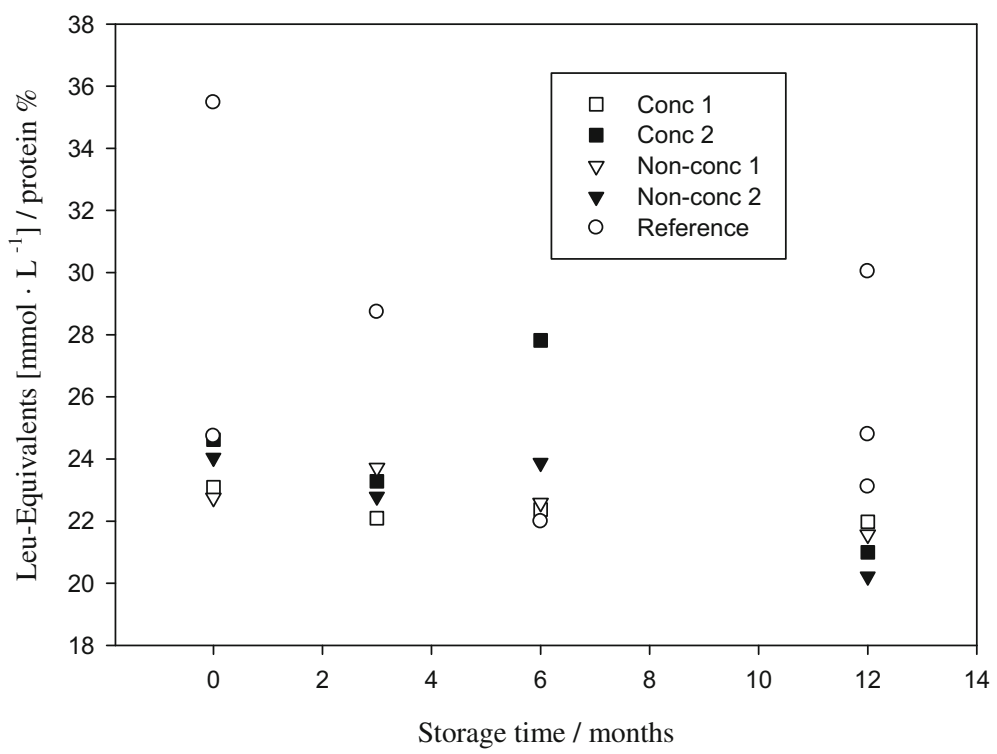

Fig. 2 Proteolysis expressed as Leucine equivalents found in whole milk powders produced from nonconcentrated (non-conc-batches 1 and 2) raw milk and pre-concentrated (conc-batches 1 and 2) raw milk manufactured on a pilot-scale spray drier and several commercial reference powders, as dependent on storage for $0,3,6$ or 12 months at room temperature of approximately $20{ }^{\circ} \mathrm{C}$

\subsection{Colour changes and furosine formation during storage of powder}

No change of colour was observed during storage, and the $\mathrm{L}^{*}, \mathrm{a}^{*}$ and $\mathrm{b}^{*}$ variables were only significantly affected by powder type (from non-concentrated milk, pre-conc. milk and various commercial whole milk powders) as seen in Fig. $4 \mathrm{a}-\mathrm{c}$. The commercial samples were on average lighter but with more colour $-\mathrm{a},{ }^{*}$ indicating greenish colour and $b^{*}$, indicating yellowish colour. The powders made from raw milk were the darkest - with the lowest $\mathrm{L}^{*}$ value — and had almost the same level of $\mathrm{a}^{*}$ and $\mathrm{b}^{*}$ as the commercial powders. The powders from pre-concentrated milk were the lowest in colour $-\mathrm{a}^{*}$ and $\mathrm{b}^{*}$ and a lightness as the reference samples.
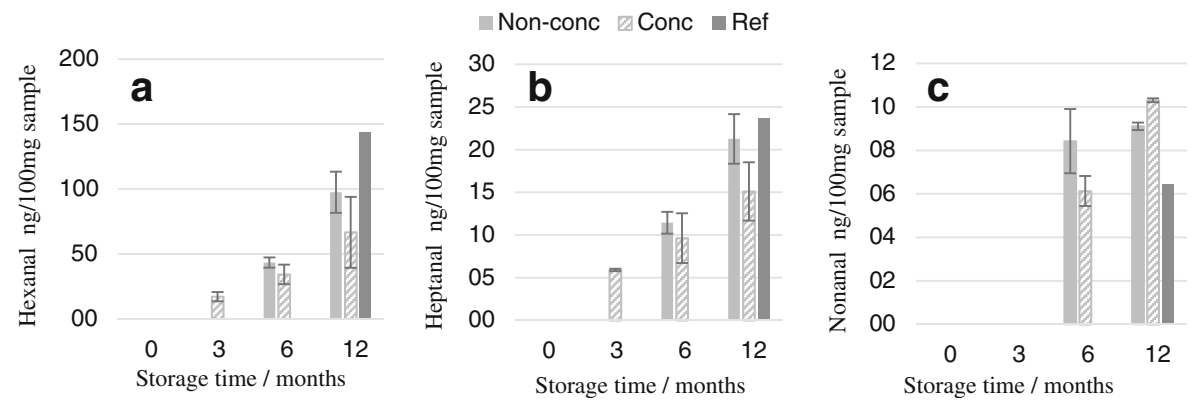

Fig. 3 Oxidation products found in powders produced from non-concentrated (non-conc) raw milk and preconcentrated (conc) raw milk manufactured on a pilot-scale spray drier, compared to a commercial reference (Ref) sample. a hexanal concentration during storage. b Heptanal concentration during storage. c nonanal concentration during storage. The error bars show the standard deviation found between the samples of same type

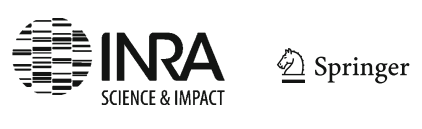




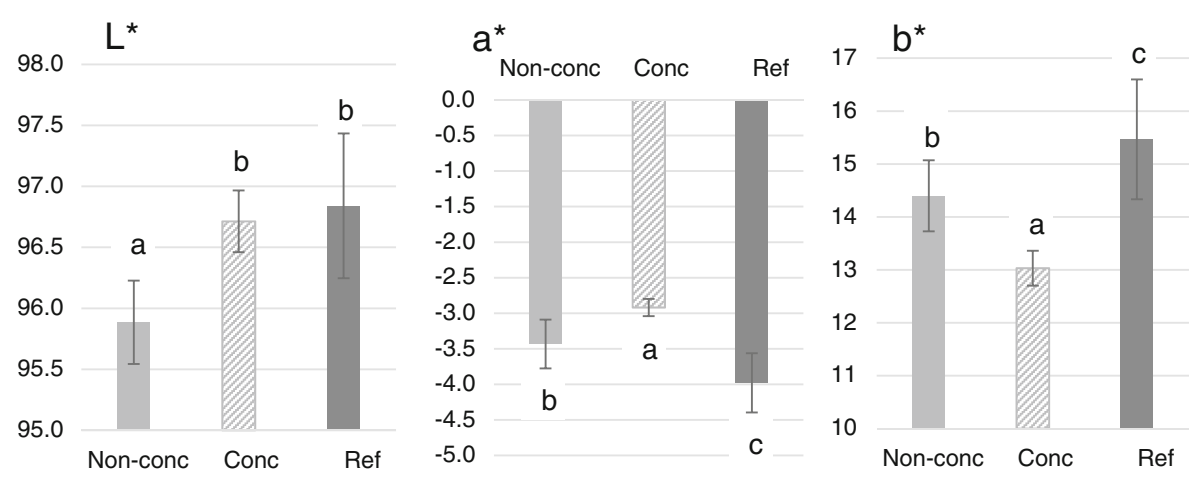

Fig. 4 Colour $L^{*}$ (lightness), $a^{*}$ (greenness) and $b^{*}$ (yellowness) as an average during storage of powders produced from non-concentrated (non-conc) raw milk and pre-concentrated (conc) raw milk manufactured on a pilot-scale spray drier, compared to several commercial reference samples (Ref) — both instant and regular, of various ages. The lower case letters $(a, b$ and $c)$ indicate significant difference between groups on the same plot $(P<0.05)$. The error bars represent the standard error of mean found between the samples of same type throughout the entire storage period

Furosine increased significantly $(P=0.03)$ upon storage of the powder samples produced from non-concentrated and pre-concentrated milk. The raw milk powder had the highest level of furosine, both before and after storage, and it was the powder type with the highest amount of protein. Furosine was positively correlated with both protein content $\left(P=0.004 ; R^{2}=0.7\right)$ and storage time, but no interaction between those factors was found by statistical analysis. The linear relation is not very evident, so a larger sample size might provide a model with better fit. When adding all the commercial reference samples, a more robust statistical model could be formed on the influence of protein and storage time on the concentration of furosine (Fig. 5). There was no correlation found between colour and furosine concentration, with the only relation being the powder composition that affects both colour and furosine.

\section{Discussion}

\subsection{Impact of powder composition and pre-concentrating milk at the farm}

In our recent study, we found that the technology of concentrating milk at the farm did not affect the milk quality regarding lipolysis and proteolysis activity (Sørensen et al. 2016) and thus theorized that the concentrated milk is still of a quality suitable for highquality milk powder production.

The powder composition had a significant effect on many of the quality parameters analysed in this study, i.e. surface free fat, proteolysis, colour and as a co-influence on the furosine concentration. The surface free fat was highly correlated with fat content as to be expected. Fitzpatrick et al. (2004) showed that it is not only the total fat content that is responsible for the final content of free fat, and Koc et al. (2003) listed a number of production factors during the spray drying process that might contribute to the final level of free fat, such as process temperature and shear stress. Surface free fat on whole milk powder might however not affect important parameters such as flow ability and hydrophobicity, since it is inevitable to have the particle surface covered in free fat, and thickness of the free 


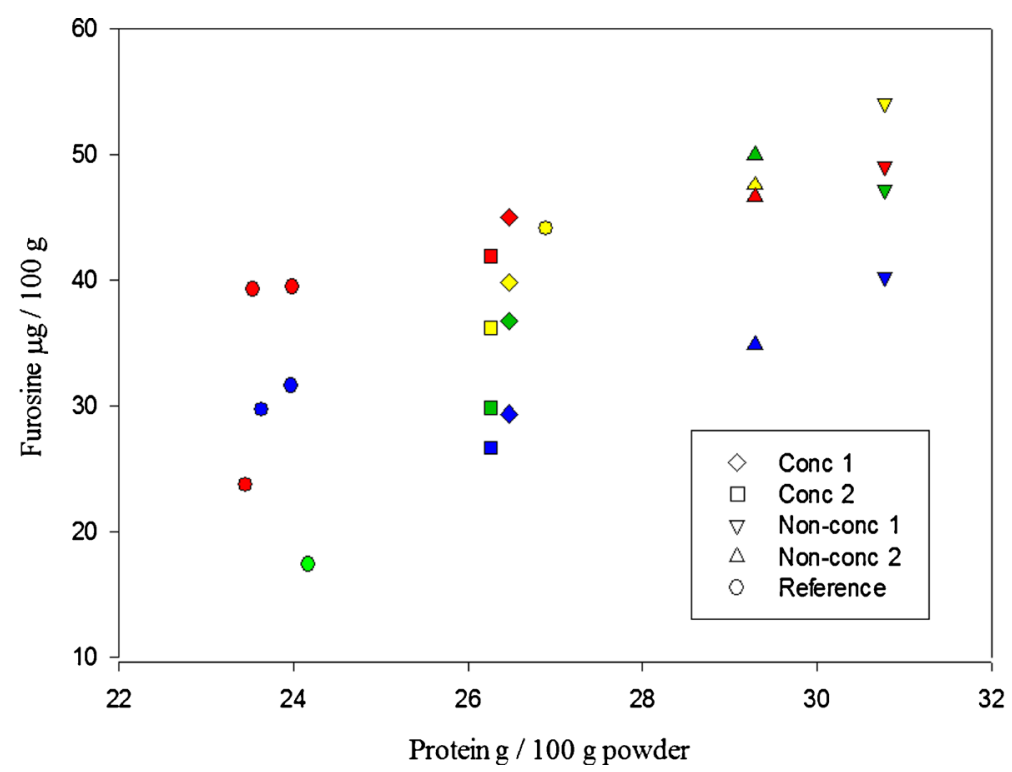

Fig. 5 Furosine formation found in whole milk powders produced from non-concentrated (nonconc-batches 1 and 2) raw milk and pre-concentrated (conc-batches 1 and 2) raw milk manufactured on a pilot-scale spray drier and several commercial reference powders, as dependent on protein content of the powders and storage time. Blue freshly produced, green 3 months, yellow 6 months and red 12 months

fat layer is not correlated to quality loss (Nijdam and Langrish 2006; Kim et al. 2009). As can be seen from the results in this study, the powders made from pre-concentrated milk had the highest amount of fat and surface free fat, but did not show any sign of poorer quality compared to the powder made from raw milk with less fat and surface free fat.

The powders from retentate and non-concentrated milk made on the small-scale industrial spray drier were characterized by most of the particles being smaller than $400 \mu \mathrm{m}$. The particle size is highly dependent on production method, including initial concentration, atomization, fluidized bed and return of fines into the drying chamber. Larger particles are associated with better wettability, flowability and lower bulk density and are therefore one of the parameters that defines instant powder (Pisecky 1997). So the particle size distribution of the powders from the small-scale production is to be expected, and the results correlate well with the study of Jin and Chen (2009), that reported particles in the size range of 100-450 $\mu \mathrm{m}$.

Celestino et al. (1997) described how certain proteolytic enzymes, especially of bacterial origin, might be resilient to the temperatures and conditions during spray drying of the milk. The proteolytic activity during storage of the powder might however be so low, that the proteolysis in the raw milk during storage before drying is still the major contributor to the total concentration of proteolytic products. Thus, the activity during powder storage may be negligible. These thoughts support the findings in this study, where no effect of storage time has been observed, neither in the powders produced from raw and pre-concentrated milk nor any of the reference samples.

Generally, the colour of milk powder is often considered in relation to Maillard reaction (Le et al. 2011). In this study, no correlation between neither storage time nor development of furosine was found, indicating that the Maillard reaction had not 
reached a level that would result in browning. It could be expected that powders with higher protein content would be more vulnerable to the heat treatment during powder manufacture Rozycki et al. (2007) since colour development in whole milk powder is faster during heat treatment, at a given temperature, with increased protein content, and this was especially the case at $\mathrm{pH}$ 6-7. Thus, this emphasizes the importance of raw material quality and production process for the final product.

Overall, the composition of the produced powders varied considerably. This made the interpretations of the influence of composition of the milk (normal or concentrated) on the resulting powder quality difficult. Even though it can be considered as a strength of the present study that an industrial low scale powder production was applied, it was also evident that there were challenges with reproducibility, due to the variability in how the concentrated and raw milk was handled before drying. It is therefore concluded that the variation between trial days and batches were larger than the contribution from variation in the milk used for spray drying.

\subsection{Storage stability in relation to oxidation and furosine formation}

In this present study, the oxidation products hexanal, heptanal and nonanal were found to increase during storage and with interaction of powder type. These oxidation components are often associated with oxidation of whole milk powders and infant formulas during storage, and they all have a rather low odour threshold (Fenaille et al. 2003; Romeu-Nadal et al. 2007). Fat and protein contents of the powder did not have a significant influence on oxidation, and the powder made from raw milk generally had a higher level of oxidation despite the lower fat content and lower surface free fat, compared to the pre-concentrated milk from the same heard. Likewise, Zunin et al. (2015) found that there is no correlation between free fat and level of oxidation. It is well known that water activity accelerates the process (Nielsen et al. 1997; Stapelfeldt et al. 1997), and in the present study, moisture content and storage interacted on the formation of hexanal and heptanal. Therefore, even though neither of the powder samples in this study have considerably high moisture content, the differences are still enough to have measurable impact on the powder quality.

Furosine is a so-called artificial amino acid that is formed by the acid hydrolysis during the analysis of the first stage Maillard reaction products. The disadvantage of using furosine as an indicator of Maillard reaction is that during the acid hydrolysis, lysine is formed together with furosine, and if the Maillard reaction is on a more advanced stage, where fructoselysine has been further degraded, furosine will not be formed. The advantages are, on the other side, that even though lysine is formed by the acid hydrolysis during analysis, the furosine formation is still consistent. So when evaluating furosine results, it is important to keep in mind whether the Maillard reaction could be on a more advanced stage (Thomas et al. 2004). In this study, no changes in colour was found during storage, indicating that the Maillard reaction was still at an initial stage and thus furosine analysis was considered to be a reliable marker. Maillard reaction is known to be accelerated by water activity (Van Renterghem and De Block 1996; Thomsen et al. 2005). Nevertheless, the results of this study indicated no correlation between moisture content of the powder and furosine formed, in contrast to the oxidation results. Protein content was, however, found to be associated with a furosine formation, in accordance with the study of Morgan et al. (2005). This supports 
the findings in our study, where a combined effect of protein content and storage time influenced the furosine formation, especially when including various commercial whole milk powder as described by the model in Fig. 5. It could be argued that nonconcentrated milk was subjected to more evaporation than pre-concentrated prior to spray drying. According to Oldfield et al. (2005), the preheat treatment is more harmful to the whey proteins than the evaporation process. Thus, it does not appear to be of any disadvantage to concentrate the milk through $\mathrm{RO}$ - even if it is conducted at the farm. Taken together, it seems like a promising method that does not have negative influence on milk quality like proteolysis, in spite of the more concentrated milk matrix and closer presence of e.g., milk enzymes and its milk substrates. However, an eventual implementation will depend on economic calculations on the feasibility and will potentially be of higher benefit in countries with long distances and extensive, but large farms.

\section{Conclusion}

The present study show that the concentration of proteolysis products depended on the powder origin and especially the commercial powders had a higher level of proteolysis. Concentration of proteolysis products did not increase during storage of any of the powders. Surface free fat was significantly correlated with the fat content of the powders. Storage time influenced the concentration of the oxidation products hexanal, heptanal and nonanal for both powder from RO retentate and from non-concentrated milk, and after 12 months, the oxidation was still in the same range as commercial whole milk powder. Furthermore, hexanal and heptanal were influenced by the moisture content. The formation of furosine was dependent on both storage time and final powder composition, but the Maillard reaction was at an early stage and thus not reflected through colour measurements. Colour did not change during storage. The raw material handling at the pilot-scale spray drier derived some compositional effect e.g., protein and fat $\%$ in the powder, which could have affected some quality parameters, epically the moisture content of the produce powders was low. However, this is a wellknown challenge when using pilot-scale instead of a real production scale. Overall, concentrating the milk at the farm prior to powder production did not affect the powder quality, compared to powder from non-concentrated milk, and thus seemed a promising procedure to avoid transport of large volumes prior to processing.

Acknowledgements We thank Søren Skjølstrup Jensen, Simon Andersen (Arla Food Ingredients, Videbæk, Denmark) and Nils Mørk (GEA Process Engineering, Skanderborg, Denmark) for the knowledge and technical assistance; Mette Krogh Larsen (Arla Arinco, Videbæk, Denmark) for acquiring reference samples and laboratory facilities; and Rita Albrechtsen and Gitte Hald Kristiansen (Aarhus University, Deparment of Food Science, Tjele, Danmark) for assisting in laboratory work.

\section{References}

AOAC (2000) Official Methods of Analysis of AOAC International. Method No. 905.02. 17th ed AOAC (2005) Official Methods of Analysis of AOAC International. Method No. 930.29. 18th ed 
Celestino EL, Iyer M, Roginski H (1997) The effects of refrigerated storage of raw milk on the quality of whole milk powder stored for different periods. Int Dairy J 7:119-127

Dalsgaard TK, Nielsen JH, Larsen LB (2007) Proteolysis of milk proteins Lactosylated in model systems. Mol Nutr Food Res 51:404-414

Fenaille F, Visani P, Fumeaux R, Milo C, Guy PA (2003) Comparison of mass spectrometry-based electronic nose and solid phase microextraction gas chromatography-mass spectrometry technique to assess infant formula oxidation. J Agric Food Chem 51:2790-2796

Fitzpatrick JJ, Iqbal T, Delaney C, Twomey T, Keogh MK (2004) Effect of powder properties and storage conditions on the flowability of milk powders with different fat contents. J Food Eng 64:435-444

Jansson $\mathrm{T}$ et al (2014) Lactose-hydrolyzed milk is more prone to chemical changes during storage than conventional UHT milk. J Agric Food Chem 62:7886-7896

Jensen BM, Nielsen JH, Sørensen J, Mortensen G, Dalsgaard TK (2011) Changing oxidation in whey fat concentrate upon addition of green tea extract. Eur Food Res Technol 233:631-636

Jin Y, Chen XD (2009) Numerical study of the drying process of different sized particles in an industrial-scale spray dryer. Dry Technol 27:371-381

Kim EH-J, Chen XD, Pearce D (2009) Surface composition of industrial spray-dried milk powders. 2. Effects of spray drying conditions on the surface composition. J Food Eng 94:169-181

Koc AB, Heinemann PH, Ziegler GR (2003) A process for increasing the free fat content of spray-dried whole milk powder. J Food Sci 68:210-216

Le TT, Bhandari B, Deeth HC (2011) Chemical and physical changes in milk protein concentrate (MPC80) powder during storage. J Agric Food Chem 59:5465-5473

Mahajan SS, Goddik L, Qian MC (2004) Aroma compounds in sweet whey powder. J Dairy Sci 87:4057-4063

Morgan F, Nouzille CA, Baechler R, Vuataz G, Raemy A (2005) Lactose crystallisation and early maillard reaction in skim milk powder and whey protein concentrates. Lait 85:315-323

Murrieta-Pazos I, Gaiani C, Galet L, Calvet R, Cuq B, Scher J (2012) Food powders: surface and form characterization revisited. J Food Eng 112:1-21

Nielsen BR, Stapelfeldt H, Skibsted LH (1997) Differentiation between 15 whole milk powders in relation to oxidative stability during accelerated storage: analysis of variance and canonical variable analysis. Int Dairy J 7:589-599

Nijdam JJ, Langrish TAG (2006) The effect of surface composition on the functional properties of milk powders. J Food Eng 77:919-925

Oldfield DJ, Taylor MW, Singh H (2005) Effect of preheating and other process parameters on whey protein reactions during skim milk powder manufacture. Int Dairy J 15:501-511

Parkin KL (2008) Enzymes. In: Damodaran S, Parkin KL, Fennema OR (eds) Fennema's food chemistry, Fourth edn. CRC Press, Boca Raton, pp. 331-435

Pisecky J (1997) Hb Milk Pow Manuf. Handbook of Milk Powder Manufacture. Niro A/S, Copenhagen.

Romeu-Nadal M, Chávez-Servín JL, Castellote AI, Rivero M, López-Sabater MC (2007) Oxidation stability of the lipid fraction in milk powder formulas. Food Chem 100:756-763

Rozycki SD, Pauletti MS, Costa SC, Piagentini AM, Buera MP (2007) The kinetics of colour and fluorescence development in concentrated milk systems. Int Dairy J 17:907-915

Sert D, Mercan E, Aydemir S, Civelek M (2016) Effects of milk somatic cell counts on some physicochemical and functional characteristics of skim and whole milk powders. J Dairy Sci 99:In press

Singh H (2007) Interactions of milk proteins during the manufacture of milk powders. Lait 87:413-423

Stapelfeldt H, Nielsen BR, Skibsted LH (1997) Effect of heat treatment, water activity and storage temperature on the oxidative stability of whole milk powder. Int Dairy J 7:331-339

Sørensen I, Jensen S, Ottosen N, Neve T, Wiking L (2016) Chemical quality of raw milk retentate processed by ultra-filtration or reverse osmosis at the dairy farm. Int J Dairy Sci 69:31-37

Thomas MEC, Scher J, Desobry-Banon S, Desobry S (2004) Milk powders ageing: effect on physical and functional properties. Crit Rev Food Sci Nutr 44:297-322

Thomsen MK, Lauridsen L, Skibsted LH, Risbo J (2005) Temperature effect on lactose crystallization, maillard reactions, and lipid oxidation in whole milk powder. J Agric Food Chem 53:7082-7090

Van Renterghem R, De Block J (1996) Furosine in consumption milk and milk powders. Int Dairy J 6:371-382

Wiking L, Frøst MB, Larsen LB, Nielsen JH (2002) Effects of storage conditions on lipolysis, proteolysis and sensory attributes in high quality raw milk. Milchwissenschaft 57:797-803

Wold JP, Skaret J, Dalsgaard TK (2015) The action spectrum for photooxidation versus the absorption spectrum of full fat bovine milk. Food Chem 179:68-75

Zunin P, Boggia R, Turrini F, Leardi R (2015) Total and "free" lipids in commercial infant formulas: fatty acid composition and their stability to oxidation. Food Chem 173:332-338 